\title{
INFLUENCE OF EMPLOYEE INVOLVEMENT IN TOTAL PRODUCTIVE MAINTENANCE PRACTICES ON JOB CHARACTERISTICS The Malaysian Scenario
}

\author{
AizzatMohd. Nasurdin \\ MuhamadJantan \\ Wong Wai Peng \\ T. Ramayah
}

The main goal of this study is to examine whether the extent of involvement in Total Productive Maintenance (TPM) practices has a positive effect on job characteristics. Data was gathered from a sample of 184 respondents derived from manufacturing companies in Malaysia. Results from the regression analyses revealed that the extent of employee's involvement in TPM practices is positively related to the five core job dimensions (skill variety, task identity, task significance, autonomy, and feedback). Theoretical and managerial implications of the findings are discussed.

Keywords: core job dimensions; Malaysia; manufacturing sector; total productive maintenance 
Gadjah Mada International Journal of Business, September-December 2005, Vol. 7, No. 3

\section{Introduction}

Globalization, technological advancements, political interventions, and economic turbulence have increased competitive pressures on manufacturing firms to perform in cost-efficient ways that are able to satisfy the everchanging needs of their customers particularly with regards to customization, quick delivery, and superb quality. Costs of production are often linked to maintenance-related activities (such as maintenance labor and materials costs) and costs incurred due to production losses. Thus, for a typical manufacturing company, serious attention should be given to the reliability of the production lines in order to achieve the highest product quality at a minimum cost, which in turn, depends on the efficient running of the company's production facilities.

To function efficiently, companies need to maintain their assets and machines. Bamber et al. (1999) added that an effective maintenance strategy will significantly add value to the production activities of a firm and subsequently its business. One of the wellknown innovative maintenance programs adopted by manufacturers is the Total Productive Maintenance(TPM). TPM is an integrated life-cycle approach that utilizes the concept of maximizing a firm's overall equipment efficiency (OEE) involving all employees through well-planned small-group activities (Shirose 1992). Al-Hassan et al. (2000) in their discussion on the role
ofTPM in business excellence enhancement viewed TPM as an innovative approach to maintenanceprogramsince it optimizes equipment effectiveness, eliminates breakdowns, and promotes autonomous maintenance via day-today activities involving the firm's total workforce.

The implementation of TPM is a rather difficult process of corporate change. In many cases, the activities aimed at achieving change do not provide the intended results (Ljungberg 1998). TPM is likely to influence the job characteristics of employees. Through TPM elements, employees' jobs are enriched and their job responsibilities become more integrated into the overall organizational system (Imai 1986; Steinbacher and Steinbacher 1993). According to McAdam and McGeough(2000), implementing TPM led to increasedresponsibilities in maintenance for both craft (mechanical and electrical) workers and operators. In Malaysia, studies relating to TPM have been somewhat limited and heavy focus has been given to investigating the antecedents of TPM implementation (for instance, Soon 1999; Anita 2000; Hassan 2000; Ramayah et al. 2002). To date, no local studies have been undertakento examine the consequences of TPM. Thus, the primary objective of this research is to investigate the impact of the extent of employees' involvement in TPM activities on their core job dimensions. 
Nasurdin etal.-Influence of Employee Involvement in TPM ...

\section{Literature Review}

\section{Total Productive Maintenance (TPM)}

TPM can be defined from two main perspectives: the Japanese and Western perspectives (Bamber et al. 1999). According to the Japanese approach, the definition of TPM encompasses five elements as follows: (1) it aims at getting the most efficient use of equipment (i.e., overall efficiency), (2) it establishes a total (company-wide) productivemaintenancesystem encompassing maintenance prevention, preventive maintenance, and improvementrelated maintenance, (3) it requires the participation of equipment designers, equipment operators, and maintenance department workers, (4) it involves every employee from top management to bottom, (5) it promotes and implements productive maintenance based on autonomous, small group activities. In sum, TPM refers to the synergistic relationship among all organizational functions, particularly between production and maintenance, in order to continuously improve product quality, operational efficiency, capacity assurance and safety (Nakajima 1988).

Although the Western approach to TPM acknowledges the definition provided by their Japanese counterparts, past Western scholars (for instance, Rhyne 1990; Hartmann 1992; Willmott 1997) provided more generic definitions of the construct that are felt to be more suited to the Western manufacturing context. According to Rhyne
(1990), TPM reflects a partnership between the maintenance and the production organizations to improve product quality, reduce waste, reducemanufacturing cost, increase equipment availability, and improve the company's overall state of maintenance. Hartmann (1992) added that TPM serves to improve the overall effectiveness of equipment with the active involvement of operators. Furthermore, TPM seeks to engender a company-wide approach towards achieving a standard of performance in manufacturing in terms of the overall effectiveness of equipment, machines, and processes (Willmott 1997). The essence of TPM is that production equipment operators share the preventive maintenance efforts, assist technicians with repairs when equipment is down, and together they work on equipment and process improvements in team activities (Maggard and Rhyne 1992). TPM experts (like Nakajima 1988; Willmott 1997) agree that a common feature of either the Japanese or Western approach to TPM is to strive for three common goals, namely zero defects, zero accidents, and zero breakdowns. These scholars also agree that the aim of TPM activities is to improve the productivity, quality costs, costs of products, delivery and the movement of products, safety of operations, and morale of the workers involved.

Although there are basically five pillars of TPM development as summarized by Nakajima (1989):(1) implement improvement activities designed to enhance equipment efficiency; (2) 
Gadjah Mada International Journal of Business, September-December 2005, Vol. 7, No. 3

establish a system of auto-nomous maintenance to be performed by equipment operators; (3) formulatea planned maintenance system; (4) develop training courses; and (5) install a system of maintenance prevention design and early equipment management, this paper will only focus on four elements in accordance to Nakajima (1988) namely focused improvement, autonomous maintenance, plannedmaintenance, and early equipment maintenance.

Focused Improvement. Focused improvement comprises of technical breakdown analysis and counter measures against major production losses. There are two types of breakdown known as function-loss breakdown and function-reduction breakdown. Function-loss breakdown refers to breakdown in which all equipment stops functioning resulting in production losses. Function-reduction breakdown relates to the deterioration of equipment, causing other losses (such as long set-up and adjustment times, frequent idling and minor stoppages, reduced manufacturing speed, and prolonged cycle times, and increased defects in process and during start-up) even when the equipment can still operate. Therefore, focused improvement emphasizes on the setting up of optimal conditions for the functioning and maintenance of equipment capabilities.

Autonomous Maintenance. In TPM, all operators are responsible in maintaining their own equipment. Each operator has to focus on seven tasks namely: the initial cleaning and restoration of the equipment, address the sources of dirt or contamination and identify areas that are difficult to clean and inspect, establish cleaning and lubrication standards, undertake overall inspection, abide by the autonomous standards and schedule, and carry out autonomous supervision to achieve continuous improvement (Nakajima 1988; Shenoy and Tan 1997). In order to do this, the operators themselves need to be trained in the relevant skills. Since these simple and routine maintenance tasks are being assigned to operators in firms pursuing TPM, maintenance specialists can now devotemore of their time on higher-level maintenance, engineering improvement, and operator training (Patterson et al. 1995).

Planned Maintenance. Planned maintenance embraces three forms of maintenance namely breakdown, preventive, and predictive. In other words, planned maintenance activities emphasize on monitoring mean times between failures (MTBF) and using that analysis to specify intervals for tasks in annual, monthly, and weekly maintenance calendar. Planned maintenance must function in tandem with autonomous maintenance. In order to lower the costs of planned maintenance, diagnostic techniques should be used to monitor equipment conditions.

\section{Early Equipment Maintenance.} There are three major categories of early equipment maintenance namely equipment development planning, life cycle costing, and maintenance prevention design. In manufacturing, equipment will need to be fabricated, installed, and tested before it is used in 
Nasurdin etal.-Influence of Employee Involvement in TPM ...

normal operations. Once the early failure period of the equipment is over, operating data will then be transmitted to the maintenance-free design state, which subsequently will be used to develop maintenance-free equipment in the future.

\section{Job Characteristics}

Job characteristics have been described as reasonably objective, measurable, and changeable properties or attributes of the work itself (Hackman and Oldham 1980). According to the Job Characteristics Model (JCM) developed by Hackman and Oldham (1980), there are five core job dimensions (skill variety, task identity, task significance, autonomy, and feedback). These attributes, in turn, will result in certain critical psychological states, which ultimately lead to greater personal and work outcomes such as higher satisfaction, greater work performance, higher internal motivation, and lower absenteeism and turnover (Hackman and Oldham 1976; Hackman and Oldham 1980).

Skill Variety. Skill variety refers to the extent to which the job requires a variety of different activities in carrying out the work, involving the use of a number of different skills and talents of the person (Hackman and Oldham 1976).

Task Identity. Task identity relates to the degree to which a job requires completion of a "whole" and identifiable piece of work, that is, doing a job from the beginning to the end with a visible outcome (Hackman and Oldham 1976).

Task Significance. Task significance reflects the degree to which the job has a substantial impact on the lives or works of other people, whether in the immediate organization or in the external environment (Hackman and Oldham 1976).

Autonomy. Autonomy refers to the degree to which the job provides substantial freedom, independence, and discretion to the individual in scheduling the work and in determining the procedures to be used in carrying it out (Hackman and Oldham 1976).

Feedback. Feedback relates to the degree to which carrying out the work activities required by the job results in the individual obtaining direct and clear information about the effectiveness of his or her performance (Hackman and Oldham 1976).

Three core job dimensions (skill variety, task identity, and task significance) are associated with the Job Characteristics Model (JCM) when in combination serve to create a meaningful work for the job incumbent (Robbins 2003). In other words, if these three characteristics exist in a job, the jobholder will view the job as being important, valuable, and worthwhile. Additionally, jobs that possess autonomy are likely to give jobholders a feeling of personal responsibility of the results. Similarly, if a job provides feedback, the individual will know how effectively he or she has performed. From a motivational viewpoint, the Job Char- 
Gadjah Mada International Journal of Business, September-December 2005, Vol. 7, No. 3

acteristics Model (JCM) suggests that job incumbents will obtain internal rewards when they learn (knowledge of results) that they personally (experienced responsibility) have performed well on a task that they care about (experienced meaningfulness). The greater the existence of these three psychological states, the greater employees' motivation, performance, and satisfaction will be; and the lower their absenteeism and likelihood of leaving the organization will be.

\section{Total Productive Maintenance and Core Job Dimensions}

TPM is bound to affect the job characteristics of employees. Through TPM, workers' jobs will be enriched and their job responsibilities will become more integrated into the overall organization system.

TPM Involvement and Skill Variety. According to Cooke (2000), as part of the TPM philosophy, both the operators and maintenance workers need to have a greater understanding of each other's function and within such context, these two categories of employees often have to acquire somenew skills. For instance, operators need to be able to carry out minor adjustments and basic preventive maintenance, such as routine checking, cleaning, and lubrication of the equipments, necessitating them to learn additional skills. The maintenance employees, on the other hand, are released from their traditional tasks of lower skill levels and are able to handle jobs which require the use of higher level and multiple skills such as in major repairs, overhauls, equipment improvements, more complex preventive maintenance, and replacement and acquisition of physical assets (Cooke 2000; Tsang and Chan 2000). McAdamand McGeough(2000) provided support for the existence of multi-skills enhancement among both operators and craft workers (mechanical and electrical) in manufacturing companies that implement TPM as a result of the greater responsibilities imposed on them. These arguments seem to suggest that involvement in Total Productive Maintenance (TPM) will have a positive influence on employees' skill variety.

TPM Involvement and Task Identity. In autonomous maintenance, operators are responsible in carrying out several maintenance tasks in steps starting from the initial cleaning of a particular equipment to continuously inspecting and improving standards (Shenoy and Tan,1997). By doing so, operators are able to complete a whole and identifiable piece of work from beginning to the end. Similarly, as gathered from past literatures (for example, Imai 1986; Cooke 2000; McAdam and McGeough 2000; Ireland and Dale 2001), the increase in job scope as a result of the greater responsibilities associated with the need to maintain and improve machine operations imposed on operators and maintenance workers are likely to enhance their sense of task identity. In sum, one can conjecture that involvement in TPM programs is likely to increase employees' feelings of task identity. 
Nasurdin etal.-Influence of Employee Involvement in TPM ...

TPM Involvement and Task Significance. It has been reported that one of the aims of TPM is to prevent quality defects (Al-Hassan et al. 2000). One way to do so is via quality maintenance, which is a set of activities requiring the identification and control of equipment components that affect variability in a product (Al-Hassan et al. 2000). As a result, the products generated would be of higher quality at lower costs, which ultimately benefit the customer leading to their satisfaction. Al-Hassan et al. (2000) also contended that the benefits from TPM may be extended to the society at large. The implementation of TPM helps prevent accidents concerning machines particularly at the production lines and subsequent contamination, thereby, minimizing any potential adverse impact on the organization's workforce as well as the environment. In other words, a person's involvement in TPM activities tends to have a significant impact on the lives of others. On the basis of this literature, it is possible to posit that employees' participation in their firm's TPM activities can have a positive effect on their task significance level.

TPM Involvement and Autonomy. Past scholars (for example, Roberts 1999; Al-Hassan et al. 2000) supported the notion of empowerment among employees in an organization that practices TPM. Workers particularly operators are given the autonomy and opportunity to look after the conditions and effectiveness of the equipments and machines within their care (Al-Hassan et al. 2000). They are al- lowed to make decisions and initiate corrective actions to prevent any unscheduled breakdowns. Under such circumstances, employees' flexibility and autonomy will be increased. Furthermore, as noted by Nakajima (1989), operators are required to participate in giving ideas and suggestions to improve the production line through small group activities, which in turn, will lead them to experiencemoreautonomy. Hence, it can be argued that involvement in TPM activities will lead to greater autonomy among employees.

TPM Involvement and Feedback. TPM as a technique helps improve interdepartmental communication especially between the maintenance, engineering, and production units (Blanchard 1997; Bamber et al. 1999; Al-Hassan et al. 2000). For instance, in focused improvement, cross-functional teams consisting of workers from different disciplines are required to participate in various activities designed at minimizing production losses. These team members need to cooperate, share information, and undertake joint-responsibilities in tandem with the partnership approach(Maggard and Rhyne 1992), thereby, increasing feedback. In addition, employees need to continually monitor the mean times between failures (MTBF) as part of their equipment assessment exercise. These data serve as a feedback for workers to initiate subsequent corrective actions. Within such a context, involvement in TPM activities is likely to result in greater feedback. 
Figure 1. Research Model

\begin{tabular}{|c|l|}
\hline \multirow{2}{|c|}{\begin{tabular}{|l|} 
Extent of Involvement \\
in TPM
\end{tabular}} & Job Characteristics \\
& Skill Variety \\
Task Identity \\
Task Significance \\
Autonomy \\
Feedback \\
\hline
\end{tabular}

Based on the above discussion, the framework used in this study is shown in Figure 1.

From Figure 1, five hypotheses were developed as follows:

$H_{l}$ : Higher extent of involvement in TPM leads to greater skill variety.

$\mathrm{H}_{2}$ : Higher extent of involvement in TPM leads to greater task identity.

$H_{3}:$ Higher extent of involvement in TPMleads to greater tasksignificance.

$H_{4}$ : Higher extent of involvement in TPM leads to greater autonomy.

$H_{5}$ : Higher extent of involvement in TPM leads to greater feedback.

\section{Methodology}

\section{Subjects}

Participants in the study were employees attached to manufacturing companies located in the northern region of peninsular Malaysia. A total of 300 questionnaires were distributed via convenience sampling. The "drop-off" and "pick-up" method was employed whereby respondents were given two weeks to answer the questionnaires. In all, 212 questionnaires were returned, of which 184 were found to be useable, representing a response rate of 61.3 percent.

\section{Measurement and Method of Analysis}

The predictor variable used in this study is the extent of an employee's involvement in TPM whilst the criterion variables relate to the five core job dimensions were skill variety, task identity, task significance, autonomy, and feedback. The extent of involvement in TPM was measured using 14 items adopted from previous literatures (for instance, Blanchard 1997; Ljungberg 1998; Maggard and Rhyne 1992). Responses to the items were made based on a 5-point scale (1= "none at all" to $5=$ "very high"). Job characteristics were measured using 15 items with 3 items each for skill variety, task identity, task significance, autonomy, and feedback. The items were adopted from the Job Diagnostic Survey (JDS) developed by Hackman and Oldham (1980). Responses to the items were 
Nasurdin etal.-Influence of Employee Involvement in TPM ...

made based on a 5-point scale $(1=$ "very little" to $5=$ "very much"). In this study, the five hypotheses were tested using simple regressions.

\section{Results}

Profiles of the samples are shown in Table 1. From Table 1, it can be observed that of the 184 respondents, $102(55.4 \%)$ were from the shop floor or operational level. In terms of age, 99 $(53.8 \%)$ respondents were below 30 years old. Regarding marital status, $102(55.4 \%)$ was married. In terms of education, $104(56.5 \%)$ have second- ary school education and lower. Additionally, 95 (51.6\%) respondents have been working for ten years and above. Descriptive statistics for the study variables were computed as depicted in Table 2.

As can be observed from Table 2 , the mean value for extent of involvement in TPM is 2.17 with a standard deviation of 0.78 . The mean score for skill variety, task identity, task significance, autonomy, and feedback, respectively are $2.54(\mathrm{SD}=0.81), 3.20$ $(\mathrm{SD}=0.34), 3.80(\mathrm{SD}=0.54), 3.35$ $(\mathrm{SD}=1.12)$, and $3.26(\mathrm{SD}=0.66)$.

Table 1. Profile of Respondents

\begin{tabular}{|c|c|c|}
\hline Demographic Variable & Categories & Percentage (\%) \\
\hline \multirow[t]{3}{*}{ Age } & Less than 30 years & 53.8 \\
\hline & $30-39$ years & 45.7 \\
\hline & 40 years and above & 0.5 \\
\hline \multirow[t]{2}{*}{ Marital Status } & Unmarried & 44.6 \\
\hline & Married & 55.4 \\
\hline \multirow[t]{5}{*}{ Education Level } & Masters and above & 4.9 \\
\hline & Undergraduate & 17.4 \\
\hline & Diploma & 21.2 \\
\hline & Secondary School & 51.6 \\
\hline & Primary School & 4.9 \\
\hline \multirow[t]{2}{*}{ Length of Service } & Less than 10 years & 48.4 \\
\hline & 10 years and above & 51.6 \\
\hline \multirow[t]{5}{*}{ Position } & Top-level management & 3.5 \\
\hline & Middle-level management & 5.4 \\
\hline & Lower-level management & 17.4 \\
\hline & Supervisors & 18.5 \\
\hline & Shop floor (Operators) & 55.4 \\
\hline
\end{tabular}


Gadjah Mada International Journal of Business, September-December 2005, Vol. 7, No. 3

Table 2. Descriptive Statistics of Study Variables

\begin{tabular}{|c|c|c|}
\hline Variable & Mean & Standard Deviation \\
\hline Extent of involvement in TPM & 2.17 & 0.78 \\
\hline Skill Variety & 2.54 & 0.81 \\
\hline Task Identity & 3.20 & 0.34 \\
\hline Task Significance & 3.80 & 0.54 \\
\hline Autonomy & 3.35 & 1.12 \\
\hline Feedback & 3.26 & 0.66 \\
\hline
\end{tabular}

Table 3. Intercorrelations of the Study Variables

\begin{tabular}{|c|c|c|c|c|c|c|}
\hline & INVOLVE & SV & TI & TS & AUT & FEED \\
\hline INVOLVE & $(.87)$ & & & & & \\
\hline SV & $.439 *$ & (.79) & & & & \\
\hline TI & $.642 *$ & .085 & (.85) & & & \\
\hline TS & $.483^{*}$ & $.378^{*}$ & $.497^{*}$ & $(.73)$ & & \\
\hline AUT & $.653^{*}$ & $.407^{*}$ & $.659 *$ & $.728 *$ & $(.90)$ & \\
\hline FEED & $.655^{*}$ & $.446^{*}$ & $.547^{*}$ & $.517^{*}$ & $.765^{*}$ & (.78) \\
\hline
\end{tabular}

Note: Abbreviations were used: "INVOLVE” for involvement in TPM, "SV" for skill variety, "TI" for task identity, "TS" for task significance, "AUT” for autonomy, and "'FEED” for feedback.

$* \mathrm{p}<0.01$; parentheses denotes the reliability coefficients.

Table 3 indicates the correlation coefficients and the reliability coefficients of the study variables. As can be observed from Table 3, the Pearson's correlations between the study variables were significant ranging from 0.378 to 0.765 . The reliability coefficients of the instruments were considered high since all the values exceeded the minimum acceptable level of 0.7 (Nunnally 1978).

In order to test the five hypotheses, extent of involvement in TPM was regressed on to the five core job dimen- sions. The analysis was done taking into consideration all the assumptions that has to be fulfilled before the interpretation can be made. The assumptions tested are linearity (tested by looking at the partial regression plots), normality of the error term (tested using the normal probability plot which did not show any major deviation from the diagonal), autocorrelation (tested using the Durbin Watson statistics, the value was 1.94 which is very close to the suggested value of 2.0), and homoscedasticity (tested through the exami- 
Nasurdin etal.-Influence of Employee Involvement in TPM ...

Table 4. Regression Results between Involvement in TPM and Job Dimensions

\begin{tabular}{|c|c|c|c|c|c|}
\hline $\begin{array}{c}\text { Independent } \\
\text { Variable }\end{array}$ & SV & TI & TS & AUT & FEED \\
\hline & Std. Beta & Std. Beta & Std. Beta & Std. Beta & Std. Beta \\
\hline $\begin{array}{l}\text { Extent of } \\
\text { Involvement } \\
\text { in TPM }\end{array}$ & $0.831 * *$ & $0.746 * *$ & $0.138^{*}$ & $0.822 * *$ & $0.495 * *$ \\
\hline R -Square & 0.639 & 0.631 & 0.045 & 0.331 & 0.340 \\
\hline
\end{tabular}

$* * \mathrm{p}<0.01, * \mathrm{p}<0.05$

nation of the residuals by plotting the studentized residual with the predicted Y, they did not show any increasing or decreasing residuals) (Hair et al. 1998). Table 4 presents the regression results after all the assumptions have been met.

From Table 4, it can be seen that the extent of involvement in TPM has a positive and significant effect on all the job dimensions. Specifically, the â-values for the five aspects associated with a job are: skill variety (0.831), autonomy (0.822), task identity (0.746), feedback (0.495), and task significance (0.138). From the regression coefficients, it can be concluded that the impact of involvement in TPM is greatest on skill variety compared to the other job dimensions. These findings provided support for $\mathrm{H}_{1}$ to $\mathrm{H}_{5}$.

\section{Discussion, Implication, and Limitation}

The main objective of this study was to examine whether the extent of involvement in TPM has positive effects on the five core job dimensions. The regression results obtained indicate that one's involvement in TPM activities increases one's perception of the level of skill variety, task identity, task significance, autonomy, and feedback. This finding is consistent with those of previous scholars (for example, Blanchard 1997; Bamber et al. 1999; Shenoy and Tan 1997; Roberts 1999; Al-Hassan et al. 2000; Cooke 2000; McAdamand McGeough,2000; Tsang and Chan 2000).

Involvement in Total Productive Maintenance (TPM) requires the operators to perform a variety of basic tasks in equipment maintenance such as routine checking, cleaning, and lubrication, which in turn, necessitates the use of additional skills. The maintainers are released from performing their traditional routine tasks and instead are required to move on to higherlevel jobs, which require the use of multiple skills such as in major repairs, overhauls, equipment improvements, 
Gadjah Mada International Journal of Business, September-December 2005, Vol. 7, No. 3

more complex preventivemaintenance, and replacement and acquisition of physical assets (Cooke 2000; Tsang and Chan 2000). In such situation, these workers are likely to experience greater skill variety in their jobs.

In a TPM practicing firm, operators are responsible in carrying out several maintenance tasks starting from initial cleaning of the equipment to continuously inspecting and improving standards (Shenoy and Tan 1997). By undertaking such sequential tasks, operators are able to complete a whole and identifiable piece of work from beginning to the end. Hence, autonomous maintenance activities carried out by operators in organizations that implement TPM are inclined to increase their sense of task identity.

Similarly, quality maintenance, one of the components in TPM, requires workers to identify and control equipment components that affect variability in a product (Al-Hassan et al. 2000). As a result, the products generated would be of higher quality at lower costs, which ultimately lead to customer satisfaction. Furthermore, the tracking and improvement of equipment performance helps prevent accidents concerning machines particularly at the production lines, thereby, minimizing any potential contamination which may have an adverse impact on the organization's workforce as well as the external environment. Thus, the significant impact made by workers in TPM practicing companies on the lives of others outside their orbit tends to increase their task significance level.
Empowerment, one of the philosophies embraced in TPM, is likely to enhance employees' sense of autonomy. For instance, in autonomous maintenance, the production operators are not only allowed to look after the conditions and effectiveness of the equipments and machines within their care, but also given the opportunity to decide and initiate corrective actions to prevent any unscheduled breakdowns (Roberts 1999; Al-Hassan et al. 2000). Within such contexts, shop floor workers or operators are likely to experience greater autonomy.

Finally, TPM helps improve crossfunctional communication particularly between the maintenance, engineering, and production departments (Blanchard 1997; Bamber et al. 1999; Al-Hassan et al. 2000). For instance, in focus improvement, cross-functional teams are created to participate in various activities designed at minimizing production losses. These team members are required to cooperate, share information, and undertake joint work responsibilities consistent with the partnership approach as espoused by Maggard and Rhyne (1992), thereby, increasing feedback. Further, the data gathered through equipment diagnostic exercise will serve as inputs for subsequent corrective actions. Under such circumstances, employees are bound to experience greater feedback.

From a practical standpoint, given the potential benefits that can be derived from the presence of core job dimensions (skill variety, task identity, task significance, autonomy, and feed- 
Nasurdin etal.-Influence of Employee Involvement in TPM ...

back) on an employee's work outcomes (like increased motivation, performance, and satisfaction as well as reduced absenteeism and turnover), it would be worthwhile for employing organizations to engage in TPM activities and encourage their workers to participate in these activities. One ob- vious limitation of this research is that since many companies do not embrace all the elements associated with TPM, respondents may not be fully aware of the TPM construct. Therefore, the responses gathered in this investigation may be somewhat biased.

\section{References}

Al-Hassan, K., J. F. L. Chan, and A. V. Metcalfe. 2000. The role of total productive maintenance in business excellence. Total Quality Management 11(4-6): 596-601.

Anita S. 2000. TPM and company performance. Unpublished MBA Thesis. Penang: Universiti Sains Malaysia.

Bamber, C. J., J. M. Sharp, and M. T. Hides. 1999. Factors affecting successful implementation of total productive maintenance: A UK manufacturing case study perspective. Journal of Quality in Maintenance Engineering 5 (3): 162-177.

Blanchard, B. S. 1997. An enhanced approach for implementing total productive maintenance in the manufacturing environment. Journal of Quality in Maintenance Engineering 3 (2): 69-80.

Cooke, F. L. 2000. Implementing TPM in plant maintenance: Some organizational barriers. International Journal of Quality and Reliability Management 17 (9): 10031016.

Hackman, J. R., and J. R. Oldham. 1976. Motivation through the design of work: Test of a theory. Organizational Behavior and Human Performance 16: 250-279.

Hackman, J.R. and Oldham, J.R. (1980). Work Redesign. Reading: Addison-Wesley.

Hair, J. F. Jr., R. E. Anderson, R. L. Tatham, and W. C. Black. 1998. Multivariate Data Analysis ( $5^{\text {th }}$ Ed.). New Jersey: Prentice-Hall, Inc.

Hartmann, E. H. 1992. Successfully Installing TPM in a Non-Japanese Plant: Total Productive Maintenance. London: TPM Press Inc.

Hasan, M. M. 2000. Effect of change management on implementation of TQM. Unpublished MBA Thesis. Penang: Universiti Sains Malaysia.

Imai, M. 1986. Kaizen: The Key to Japan's Competitive Success. New York: McGrawHill Publishing Company.

Ireland, F., and B. G. Dale. 2001. A study of total productive maintenance implementation. Journal of Quality and Maintenance Engineering 7 (3): 183-190.

Ljungberg, O. 1998. Measurement of overall equipment effectiveness as a basis for TPM activities. International Journal of Operations and Production Management 18(5): 495-507. 
Gadjah Mada International Journal of Business, September-December 2005, Vol. 7, No. 3

Maggard, B. N., and D. M. Rhyne. 1992. Total productive maintenance: A timely integration of production and maintenance. Production and Inventory Management Journal 33 (4): 6-10.

McAdam, R., and F. McGeough. 2000. Implementing total productive maintenance in multi-union manufacturing organizations: Overcoming job demarcation. Total Quality Management 11 (2): 187-197.

Nakajima, S. 1988. TPM: Introduction to Total Productive Maintenance. MA: Productivity Press.

Nakajima, S. 1989. TPM Development Program: Implementing Total Productive Maintenance. MA: Productivity Press.

Nunnally, J. C.1978. Psychometric Theory ( $2^{\text {nd }}$ Ed.). New York:McGraw-Hill.

Patterson, W. J., W. J. Kennedy, and L. D. Fredendall. 1995. Total productive maintenance is not for this company. Production and Inventory Management Journal 36 (2): 61-64

Ramayah, T., M. Jantan, and M. M. Hassan. 2002. Change management and implementation of Total Productive Maintenance: An exploratory study of Malaysian manufacturing companies. Utara Management Review 3 (1): 35-49.

Raouf, A., and M. Ben-Daya. 1995. Total maintenance management: A systematic approach. Journal of Quality in Maintenance Engineering 1 (1): 6-14.

Rhyne, D. M. 1990. Total plant performance advantages through total productive maintenance. APICS Conference Proceedings: 683-686.

Roberts, J. 1999. TPM history and basic implementation process. Internet: www.tpmonline.com/articles/tpm/tpmroberts.htm.

Robbins, S. P. 2003. Organizational Behavior (10 ${ }^{\text {th }}$ Ed.). New Jersey: Pearson Education, Inc.

Shenoy, G. V., and W. W. Tan. 1997. Productivity improvement through total productive maintenance: A case study. Asian Academy of Management Journal 2 (1 and 2): 109-127.

Shirose, K. 1992. TPM For Operators. Portland: Productivity Press.

Soon, N. K. 1999. The impact of quality management system on the organizational performance of manufacturing companies in the state of Penang. Unpublished MBA Thesis. Penang: Universiti Sains Malaysia.

Steinbacher, H., and N. Steinbacher. 1993. TPM for America. Portland: Productivity Press.

Tsang, A. H. C., and P. K. Chan. 2000. TPM implementation in China: A case study. The International Journal of Quality and Reliability Management 17(2): 144-152.

Willmott, P. 1997. TPM-Total Productive Maintenance: The Western Way. Oxford: Butterworth-Heinemann. 